\title{
Study of histopathological pattern of soft tissue tumours in tertiary care centre of Gandhi Nagar, Gujarat
}

\author{
Solanki P.1, Mangar U.2 \\ ${ }^{1}$ Dr. Piyush Solanki, Associate Professor, Department of Pathology, GMERS Medical College, Dharpur-Patan (N.G.), \\ Gujatrat, India. ${ }^{2}$ Dr. Urvashi Mangar, Assistant Professor; Department of Pathology, GMERS Medical College, \\ Vadnagar, Gujatrat, India.
}

Corresponding Author: Dr. Urvashi Mangar, 138, Sector-27, Anand Nagar, Gandhinagar, Gujarat, India. E-mail: managarurvashi@gmail.com

\begin{abstract}
Background: Soft tissue tumours are a diverse and fascinating group of lesions that arise from the supporting soft tissue of the body. Although pathologically diverse, they frequently exhibit similar clinical presentations and radiological features. Correct histopathological diagnosis is therefore crucial. Aims and objectives: This study aims to analyze the histopathological patterns of soft tissue tumours and their distribution according to age, sex and site of occurrence in patients. Methods: This study comprised of 170 cases of soft tissue tumours received in the Department of Pathology, GMERS Medical College, Gandhinagar were analysed. Their gross features, microscopic findings were analysed in detail. Soft tissue tumours were divided into benign and malignant categories and their further sub typing were done according to WHO Classification. The distribution of soft tissue tumours according to the age, sex and site of occurrence was studied. Results: Out of 170 cases of soft tissue tumours, 158 cases $(92.4 \%)$ were benign, 2 cases (1.18\%) were malignant and 10 cases $(5.88 \%)$ were classified under intermediate category. Adipocytic tumors formed the largest group constituting 92 cases (46\%). Vascular tumors were the second commonest $(7 \%)$ followed by peripheral nerve sheath tumours (10.5\%). The benign tumours were seen in younger age as compared to malignant tumours. Conclusion: Benign tumours were more common than malignant. The most common benign tumours were lipoma followed by hemangioma $(14.0 \%)$ and schwannoma (5.5\%). There is wide range of their distribution according to age, sex and site. The benign tumours were seen in younger age as compared to malignant tumours.
\end{abstract}

Keywords: Adipocytic, Histopathology, Malignant, Soft Tissue Tumours.

\section{Introduction}

Soft tissue is defined as the complex of non epithelial extra skeletal structures of the body exclusive of the supportive tissue of the various organs and the hematopoietic/lymphoid tissue. It is composed of fibrous tissue, adipose tissue, skeletal muscle, blood and lymph vessels and peripheral nervous system. Soft tissue tumors are a diverse and fascinating group of lesions that arise from the supporting soft tissue of the body [1].

Within the various histogenetic categories, soft tissue tumors are usually divided into benign and malignant forms [2]. The large majority of soft tissue tumours are benign, with a very high cure rate after surgical excision. Malignant mesenchymal neoplasms amount to less than $1 \%$ of the overall human burden of malignant tumours but they are life threatening and may pose a

Manuscript received: $10^{\text {th }}$ December 2018

Reviewed: $20^{\text {th }}$ December 2018

Author Corrected: $28^{\text {th }}$ December 2018

Accepted for Publication: $31^{\text {st }}$ December 2018 significant diagnostic and therapeutic challenges Since there are more than 50 histological subtypes of soft tissue tumours which are often associated with unique clinical, prognostic and therapeutic features. Immunohistochemistry is used to detect tumor specific alterations which add significantly to histological interpretation, but several groups of tumors still lack reliable immuno-histochemical markers [3].

At least one-third of the benign tumours are lipomas, one-third fibrohistiocytic and fibrous tumours, $10 \%$ vascular tumours and 5\% nerve sheath tumours. There is a relation between the type of tumour, symptoms, location and patient's age and gender. Lipomas are painless, mostly occurs in fatty tissue like abdomen, thigh and back. It is rare in hands, lower legs and foot and very uncommon in children. Multiple (angio) lipomas are sometimes painful and most common in young men. Angioleiomyomas are often painful and common in lower leg of middle-aged women, whereas 
Original Research Article

half of the vascular tumours occur in patients younger than 20 years [4]. Of the benign soft tissue tumours $99 \%$ are superficial and $95 \%$ are less than $5 \mathrm{~cm}$ in diameter. Soft tissue sarcomas may occur anywhere but three fourths are located in the extremities (most common in thigh) and 10 percent each in the trunk wall and retro peritoneum.

There is a slight male predominance. Like almost all other malignancies, soft tissue sarcomas become more common with increasing age; the median age is 65 years. Of the extremity and trunk wall tumours onethird are superficial with a median diameter of $5 \mathrm{~cm}$ and two-thirds are deep seated with a median diameter of 9 $\mathrm{cm}$. Retroperitoneal tumours are often much larger before they become symptomatic. One tenth of the patients have detectable metastases (most common in the lungs) at diagnosis of the primary tumour. Overall, at least one-third of the patients with soft tissue sarcoma die because of tumour metastasis mostly into the lung.

Three fourth of soft tissue sarcomas are histologically classified as high grade pleomorphic (malignant fibrous histiocytoma [MFH]-like) sarcoma, liposarcoma, leiomyosarcoma, synovial sarcoma, and malignant peripheral nerve sheath tumours and three fourth are highly malignant. The age-related incidences vary; embryonal rhabdomyosarcoma occurs almost exclusively in children, synovial sarcoma mostly in young adults, whereas pleomorphic high grade sarcoma, liposarcoma and leiomyosarcoma dominate in the elderly [5].

The two most widely used grading systems are the NCI (United States National Cancer Institute) system and the FNCLCC (French Fédération Nationale des Centres de Lutte Contre le Cancer) System. We accessed the cases received in our department according to FNCLCC grading system [6].

\section{Aims and Objectives}

This study aims to analyze the histopathological patterns of soft tissue tumors and their distribution according to age, sex and site of occurrence in patients.

\section{Material and Methods}

Study Design: The present study was carried out at histopathology section of pathology department of GMERS Medical College and General Hospital, Gandhinagar, a tertiary care centrein Gandhinagar district of Gujarat state, India during the period of March 2013 to December 2015.

Type of study: Retrospective

Data collection procedure: In present study, we analysed all 170 cases which received for histopathology examination under the diagnosis of soft tissue tumours from surgical department. We also include small biopsies also.

Inclusion criteria: All the mesenchymal tumours arising from any soft tissue like fibrous tissue, adipose tissue, skeletal muscle, blood and lymph vessels and peripheral nervous system were included in this study.

Exclusion criteria: All the non-mesenchymal tumors, bone tumors and any known already diagnosed tumours were excluded from the study.

All relevant clinical details were obtained from patients or his relatives. Each received surgical specimen in Histopathology Section were examined grossly for its size, shape, weight, consistency and appearance. Tissue cut surface was also examined for the presence of hemorrhage, necrosis and cystic spaces etc. Presence or absence of any gross involvement of adjacent structure along with depth of the tumor was also noted. All these specimens were preserved in $10 \%$ neutral buffered formalin for fixation for 24 hours.

For histopathological evaluation, numbers of sections were taken from different representative sites according to the size of specimen. While in case of small biopsy specimen the whole specimen was processed. These representative sections were subjected for processing on automatic tissue processor. After processing the section were embedded in paraffin, cut with microtome at 5 micron thickness and stained with Hematoxylin and Eosin stain. Special staining procedure like Periodic Acid Schiff (PAS) and Reticulin stains were also done as and when required.

Histological sub typing was done according to WHO classification of soft tissue tumours 2002. The sarcomas were further graded according to FNCLCC grading system in to grades 1,2, and 3 respectively. Other informations like age, sex and detail significant history were retrieved from the medical reports.

Out of total 170 cases, 92 cases (54.1\%)

\section{Results}

were males and 78 cases $(45.9 \%)$ were females with male to female ratio 1.18:1. Benign tumours were seen more in males and intermediate \& malignant in females.

Pathology Update: Tropical Journal of Pathology \& Microbiology Available online at: www.pathologyreview.in 605 | P a g e 


\section{Original Research Article}

Table-1: Sex Distribution of the Cases.

\begin{tabular}{|c|c|c|c|c|c|}
\hline Total Cases & Male & \% & Female & \% & M:F Ratio \\
\hline 170 & 92 & 54.1 & 78 & 45.9 & $1.18: 1$ \\
\hline
\end{tabular}

The most common site of soft tissue tumours as a whole is head and neck, followed by upper limb. Although benign tumours were seen to be maximum in head \&neck, where as intermediate in upper limb, and malignant tumours showed a predilection for lower limb.

Table-2: Distribution of Soft Tissue Tumours According to Tumour Differentiation and Type of neoplasm

\begin{tabular}{|c|c|c|c|c|c|c|}
\hline Tumor Differentiation & Benign & $\%$ & Intermediate & $\%$ & Malignant & $\%$ \\
\hline Adipocytic & 113 & 66.4 & 1 & 0.59 & 1 & 0.59 \\
\hline Vascular & 19 & 11.18 & 0 & 0.00 & 0 & 0.00 \\
\hline $\begin{array}{l}\text { Peripheral Nerve Sheath } \\
\text { Tumours }\end{array}$ & 11 & 6.47 & 0 & 0.00 & 1 & 0.59 \\
\hline Fibroblastic & 4 & 2.35 & 1 & 0.59 & 0 & 0.00 \\
\hline Fibrohistiocytic & 8 & 4.71 & 0 & 0.00 & 6 & 3.53 \\
\hline Smooth Muscle & 0 & 0.00 & 0 & 0.00 & 2 & 1.18 \\
\hline Skeletal Muscle & 0 & 0.00 & 0 & 0.00 & 0 & 0.00 \\
\hline chondro-osseous tumour & 1 & 0.59 & 0 & 0.00 & 0 & 0.00 \\
\hline $\begin{array}{l}\text { Tumours of uncertain } \\
\text { differentiation }\end{array}$ & 1 & 0.59 & 0 & 0.00 & 0 & 0.00 \\
\hline Could not be classified & 1 & 0.59 & 0 & 0.00 & 0 & 0.00 \\
\hline Total & 158 & 92.40 & 2 & 1.18 & 10 & 5.88 \\
\hline
\end{tabular}

Out of total 170 cases, 158 cases $(92.4 \%)$ were benign, 2 cases $(1.18 \%)$ were malignant and 10 cases (5.88\%) were classified under intermediate category. Adipocytic tumours formed the largest group consisting of 114 cases (67.06\%). Vascular tumours were the second commonest consisting of 19 cases $(11.1 \%)$ followed by peripheral nerve sheath tumours constituting 11 cases $(6.47 \%)$.

Table-3: Age Distribution of the Cases

\begin{tabular}{|c|c|c|c|c|c|c|}
\hline Age (years) & Benign & $(\%)$ & Intermediate & $(\%)$ & Malignant & $(\%)$ \\
\hline Up to 10 & 6 & 3.80 & 1 & 50 & 0 & 0 \\
\hline $11-20$ & 10 & 6.33 & 1 & 50 & 1 & 10 \\
\hline $21-30$ & 34 & 21.52 & 0 & 0 & 0 & 0 \\
\hline $31-40$ & 24 & 15.19 & 0 & 0 & 0 & 0 \\
\hline $41-50$ & 43 & 27.22 & 0 & 0 & 2 & 20 \\
\hline $51-60$. & 18 & 11.39 & 0 & 0 & 5 & 50 \\
\hline $61-70$ & 13 & 8.23 & 0 & 0 & 1 & 10 \\
\hline $71-80$ & 10 & 6.33 & 0 & 0 & 1 & 10 \\
\hline Total & 158 & 100 & 02 & 100 & 10 & 100 \\
\hline
\end{tabular}

Majority of the benign and intermediate tumours were superficial in location, which included dermis and subcutis. However, malignant soft tissue tumours were deeper in location, which included tumours arising from muscle, deep to muscle. Adipocytic tumours constituted 116 cases $(68.24 \%)$ of all soft tissue tumours, out of which 114 cases were benign 1 intermediate and 1 were malignant. Among adipocytic tumours, males outnumbered the females. The most common site of benign adipocytic tumours was upper limb and trunk whereas of malignant adipocytic tumours was lower limb. 


\section{Original Research Article}

The vascular tumours were the 2nd most common soft tissue tumours and also the 2nd most common benign tumours, the majority of which was hemangiomas. There was a wide range of age distribution in benign vascular tumours, most commonly diagnosed in $-3^{\text {rd }}$ and $4^{\text {th }}$ decades. Of the 19 vascular tumours, 10 were males and 9 were females with a M: F being 1.1. Of the benign vascular tumours, 10 cases were seen in head $\&$ neck region followed by 9 cases in the upper limb.

Out of all soft tissue tumours, 12 cases were diagnosed as peripheral nerve sheath tumours (7.06\%). Out of themwere11 cases benign 1 malignant, out of which 10 cases were of schwannoma and 1neurofibroma. These tumours showed a wide range of age distribution, majority were seen in 11-30 years of age i.e. in younger age. Of the 12 peripheral nerve sheath tumours reported, 7 were males and 4 were females.

Out of 4 fibroblastic tumours, 3 cases were of benign and 1 belonged to intermediate category. Among the 4 benign cases, 1 case benign fibrous tumor, 1 nodular fasciitis, 1 angiomyofibrblastoma, 1 fibromatosis. The benign fibroblastic tumours showed a wide range of age distribution from 2 nd to 7 th decade. Most of the benign and intermediate fibroblastic tumours were superficial in location.

Among 14 tumours of fibrohistocytic differentiation, 8cases were diagnosed as benign and 6 belonged to malignant category. Fibrohistiocytic tumours showed a wide range of age distribution from 2nd decade to 8 th decade of life. Out of 8 benign cases, 6 were seen in lower limb followed by 2 cases in upper limb. All the 6 malignant cases reported in thigh. Only 2 cases $(1.18 \%)$ smooth muscle differentiation diagnosed were of malignant category in our study. Both cases were diagnosed in $7^{\text {th }}$ decade.

\section{Discussion}

Soft tissue is defined as the supportive tissue of various organs and the nonepithelial, extra skeletal structures exclusive of lymphohematopoietic tissues. It includes fibrous connective tissue, adipose tissue, skeletal muscle, blood/lymph vessels, and the peripheral nervous system. Soft-tissue tumors constitute a large and heterogeneous group of neoplasms. Traditionally, tumors have been classified according to histogenetic features. However, histomorphologic, immunohistochemical, and experimental data suggest that most sarcomas arise from primitive, multipotential mesenchymal cells [7].

Benign tumors of soft tissue are more common than benign tumors of bone. They can occur at almost any site, both within and between muscles, ligaments, nerves, and blood vessels. These tumors vary widely in appearance and behavior. Some tumors can be quite aggressive. Invasion of nearby tissues increases the chance of an incomplete excision and the possibility that the tumor will come back [8]. Soft tissue tumors are relatively rare and constitute less than $1 \%$ of all the cancers. Benign mesenchymal tumors outnumbered sarcomas by the factor of at least 100.The annual clinical incidence of benign soft tissue tumors has been estimated up to $3000 /$ million population i.e.-less than $1 \%$ of all the malignant tumors [9]. Lipomas are the most common neoplasm of mesenchymal origin arising in any location where fat is present. At least one third of benign tumors are lipomas, one third are fibrohistiocytic tumors and fibrous tumors, $10 \%$ are vascular and $5 \%$ are nerve sheath tumors [10]
In the present study, 170 soft tissue tumours were analyzed, out of which 158 cases $(92.40 \%)$ cases were benign, 2 cases (1.18\%) were intermediate and 10 cases $(5.88 \%)$ were malignant tumours. This is in concordance with the study conducted by Agravat et al [1] who analyzed 100 cases of soft tissue tumours $(n=94)$ and tumour like lesions $(n=6)$, of which benign tumours formed the bulk, the results of which are shown in the table below. In another large scale study of 8686 cases done by Stout [11] 84.5\% tumours belonged to benign category and $15.5 \%$ to malignant category.

The age of the patients in our study ranged from 1 months to 79 years. Benign tumours were found to be more common in younger population where as malignant tumours were commoner in 5 th to $6^{\text {th }}$ decade of life. This result was in concordance with studies conducted by Agravat et al [1] and Wimber et al [12] according to them benign tumours were commoner in younger age group as compare to malignant tumours which were recorded maximum in 60-70 years age group. In our study, 92 males and 78 females were included.

The male to female ratio was $1.18: 1$. An overall incidence of soft tissue tumours was higher in males. This observation is in concordance with the studies conducted by Trojani et al [13] Jemal et al [14] Gustafson [15] Ducimetiere et al [16] as shown in table below. The slight discrepancy was due to the fact that the later studies were done on sarcomas only and benign tumours were not included. 


\section{Original Research Article}

However, Agravat et al [1] did not find any sex predilection in his study, according to their study males and females were equally affected. Head and neck was found to be the most common site involved by benign tumors and benign vascular tumors were seen to be the most common tumors at this site constituting 23 out of 36 cases occurring in this region. These findings are in agreement with the study conducted by Makino et al [17] who analysed 651 soft tissue tumors arising in the head \& neck region and found that $96 \%$ tumors $(n=628)$ were benign while only $4 \%$ were malignant. The bulk of benign tumours in his study was formed by haemangiomas $(47 \%)$ followed by adipocytic tumours (19\%). In the present study, lower limb was the most common site affected by sarcomas. This observation is in agreement with the study of 1660 sarcoma cases done by Mastrangelo et al [18] who observed lower limb $(n=329)$ to be the most common site of sarcoma followed by stomach.

In our study, visceral mesenchymal tumours were excluded. This finding is also comparable to studies conducted by Coindre et al [19] and Talati et al [20] who also found lower limb (extremities) to be the most common site involved by sarcomas.

In our study of 170 cases, the most frequent tumors were of adipocytic differentiation constituting $67.58 \%$ $(n=115)$ followed by $11.18 \%(n=19)$ cases of vascular tumours. Third in frequency were peripheral nerve sheath tumours $(\mathrm{n}=12 ; 7.06 \%)$. These observations were somewhat similar to the study conducted by Harpal et al [21].

\section{Conclusion}

Pal et al; Benign tumors were more common than malignant. Painless mass was the most common presenting symptom in our study. The most common benign tumors were lipoma, hemangioma and schwannoma. The commonest malignant tumors were malignant fibrous histiocytoma and leiomyosarcoma. The benign tumors were found to be commoner inyounger population where as malignant tumors were seen in 5 th to 6 th decade. Statistically highly significant correlation was found between age and the category of tumor.

The most common site of soft tissue tumors as a whole was head \& neck, followed by upper limb. Among benign tumors, hemangiomas had a predilection for head \& neck while lipomas were seen commonly in upper limb. Most favoured site for malignant tumor was lower limb. The second most common site involved by sarcomas was abdomen. The benign soft tissue tumors were found to be superficial in location, while malignant tumors were deep.

Importance of this study: This is important to know the different variety of pattern of soft tissue tumours in Gandhi Nagar district.

Author contribution: First author Dr. Piyush Solanki has collected all data and done study in his own institute. Second and corresponding author Dr. Urvashi Mangar has prepared the study design and drafted manuscript in presentable manner for publication in journal.

Findings: Nil; Conflict of Interest: None initiated Permission from IRB: Yes

\section{References}

1. Agravat AH, Dhruva GA, Parmar SA. Histopathology study of Soft Tissue Tumours and Tumour like Lesions. J. cell and Tissue Research. 2010; 10(2):2287-92

2. Weiss SW, Goldblum JR. General Considerations.In: Schmitt W, Black S, MacSween L, editors. Soft Tissue Tumors. 5th ed. Philadelphia: Mosby Elsevier. 2008; $1-14$.

3. Thway K. Pathology of soft tissue sarcomas. Clin Oncol (R Coll Radiol). 2009 Nov;21(9):695-705. doi: 10. 1016/j.clon.2009.07.016. Epub 2009 Sep 6.

4. Kathrin Katenkamp, Detlef Katenkamp. Soft tissue tumour- New perspectives on classification and diagnosis. Dtsch Arztebl Int. 2009 Sep; 106(39):632-6. Doi: 10.3238/arztebl.2009.0632

5. Jemal A, Siegel R, Ward E, et al. Cancer statistics, 2006. CA Cancer J Clin. 2006 Mar-Apr; 56 (2):106-30.

6. Fletcher CDM, Sundaram M, Rydholm A, Coindre JM, Singer. Soft Tissue Tumors: Epidemiology, clinical features, histopathological typing and grading. In: Fletcher CDM, UnniKK, Mertens F, editors. Pathology and Genetics of Tumors of Soft Tissue and Bone. Lyon: IARC. 2002;12-18.

7. Agarwal V, Greenebaum E, Wersto R, et al. DNA ploidy of spindle cell soft-tissue tumors and its relationship to histology and clinical outcome. Arch Pathol Lab Med. 1991 Jun;115(6):558-62.

8. Marcus SG, Merino MJ, Glatstein E, et al. Long-term outcome in 87 patients with low-grade soft-tissue sarcoma. Arch Surg. 1993 Dec;128(12):1336-43. 


\section{Original Research Article}

9. Fletcher CDM, Unni KK, Mertens F (Eds): WHO classification of tumors: Pathology and genetics of soft tissue and bones. IARC press, Lyon 2002;p12-6

10. Preeti Rihal Chakrabarti, Suvadip Chakrabarti, Ajita Pandit, Purti Agrawal, Shilpi Dosi, Mukul Raj Jain. Histopathological study of soft tissue tumors: A three year experience in tertiary care centre. Indian Journal of Pathology and Oncology, July - September 2015;2 (3); 141-149

11. Stout AP. Tumors of the soft tissues. In: Atlas of Tumor Pathology, Section II, Fascicle 5, Armed Forces Institute of Pathology 1st ed. Washington, D.C: Armed Forces Institute of Pathology. 1953:p9-128.

12. Wibmer $\mathrm{C}$, Leithner $\mathrm{A}$, Zielonke $\mathrm{N}$, et al. Increasing incidence rates of soft tissue sarcomas? A populationbased epidemiologic study and literature review. Ann Oncol. 2010 May;21(5):1106-11. doi: 10.1093/annonc/ mdp415. Epub 2009 Oct 25.

13. Trojani M, Contesso G, Coindre JM, et al. Softtissue sarcomas of adults; study of pathological prognostic variables and definition of a histopathological grading system. Int J Cancer. 1984 Jan 15;33 (1):37-42.

14. Jemal A, Siegel R, Ward E, et al. Cancer statistics, 2007. CA Cancer J Clin. 2007 Jan-Feb;57(1):43-66.

15. Gustafson P. Soft tissue sarcoma. Epidemiology and prognosis in 508 patients. Acta Orthop Scand Suppl. 1994 Jun;259:1-31.
16. Ducimetière F, Lurkin A, Ranchère-Vince $D$, et al. Incidence of sarcoma histotypes and molecular subtypes in a prospective epidemiological study with central pathology review and molecular testing. PLoS One. 2011; 6(8): e20294. doi: 10.1371/journal. pone. 0020294. Epub 2011 Aug 3.

17. Makino Y. A clinicopathological study on soft tissue tumors of the head and neck. Acta Pathol Jpn. 1979 May; 29(3):389-408.

18. Mastrangelo $\mathrm{G}^{1}$, Coindre $\mathrm{JM}$, Ducimetière $\mathrm{F}$, et al. Incidence of soft tissue sarcoma and beyond: a population-based prospective study in 3 European regions. Cancer. 2012 Nov 1;118(21):5339-48. doi: 10. 1002/cncr.27555. Epub 2012 Apr 19.

19. Coindre JM, Terrier P, Guillou L, et al. Predictive value of grade for metastasis development in the main histologic types of adult soft tissue sarcomas: a study of 1240 patients from the French Federation of Cancer Centers Sarcoma Group. Cancer. 2001 May 15;91(10): 1914-26.

20. Talati N, Pervez S. Soft tissue sarcomas: pattern diagnosis or entity? J Pak Med Assoc. 1998 Sep;48 (9): 272-5.

21. Harpal S, Richika, Ramesh K. Histopathological Pattern of Soft Tissue Tumours in 200 Cases. Ann. Int. Med. Den. Res. 2016; 2(6):PT06-PT11. doi: 10.21276/ aimdr.2016.2.6.PT2

\section{How to cite this article?}

Solanki P, Mangar U. Study of histopathological pattern of soft tissue tumours in tertiary care centre of Gandhi Nagar, Gujarat. Trop J Path Micro 2018;4(8):604-609.doi: 10.17511/jopm.2018.i08.10. 